\title{
MAIS UM NO OCEANO
}

\author{
Paula Glenadel
}

Por que escreve?

A pergunta, sabiamente, engole o pronome, o você, e se coloca na terceira pessoa. Isso colabora com a resposta, pois eu vou transitar entre o "por que você escreve" e o "por que escreve". Entre o pessoal e o impessoal. Entre eu (meu sobrenome é maior) e a ficção que inventei, um autor de literatura, de poesia, uma poeta, a Paula Glenadel.

Também me faço esta pergunta, periodicamente, e lhe acrescento outras. Por que escrevo? Por que a Paula Glenadel escreve? Por que eu tenho que explicar o que ela faz? Tentarei responder a essa pergunta brevemente, mas não tão brevemente. Porque a pergunta soa também como um paradoxo, ou inclusive como um oxímoro, ao qual eu poderia ter a tentação de responder por uma boutade, se isso não fosse uma ironia demasiado rápida, uma facilidade excessiva e bastante autocomplacente, à qual também me inclinaria a minha formação muito influenciada pela cultura francesa, com suas imensas qualidades e seus automatismos mesquinhos: escrevo para não ter que dizer porquê.

E aqui começo a pensar em um caminho para essa resposta, já que há muitos caminhos possíveis. Em geral, pensando na questão global da escrita, mas também em particular, com variações para cada um dos livros que escrevi. 
Posso afirmar que comecei a escrever para me desintoxicar de uma escrita que é comprometida com o porquê, e não somente com ele, mas também com o como, e o quando, e o onde. Estes dois últimos são, talvez, mais fáceis de resolver, porque me aparecem como basicamente enciclopédicos - embora o fundamento metafísico e antropomórfico das datações e dos contextos possa e deva ser eternamente questionado. Contudo, o porquê e o como são mais propriamente críticos.

Então, face a essa escrita crítica (cri-cri) que precisa ter rigor, o rigor, essa característica que aparece nas teses, mas também nos cadáveres, a outra escrita, a escrita literária, se apresentou para mim como uma possibilidade de respirar, uma janela para outra paisagem, com um ar mais fresco, um horizonte mais vasto....

O mais interessante é que, passados onze anos desde o momento em que assumi essa escrita (publiquei o primeiro livro de poemas em 1999), a escrita crítica ficou mais leve. São coisas bem diferentes: por um lado, frequentar sempre o mesmo lugar por falta de opção, por outro lado, frequentar um lugar com a consciência de que há outros lugares aonde se pode ir. Essa cripta ficou, portanto, mais aceitável desde que foi dotada de uma saída de emergência, e pude voltar a gostar dela.

Eu poderia perguntar também: por que é que optei primeiramente por esse lugar crítico? Fui ser professora, orientadora, pesquisadora, em suma, leitora profissional, porque imemorialmente eu gostava de ler literatura e, mais tarde, filosofia e crítica também. $\mathrm{O}$ meu gosto pelos livros poderia ter me inspirado imediatamente o desejo de ser escritora. Mas eu não conseguia imaginar ser alguém que pudesse viver unicamente de escrever literatura. E, efetivamente, ainda não consigo.

O primeiro livro que eu consegui agarrar para ler, aos seis ou sete anos de idade, foi Os trabalhadores do mar do Victor Hugo; obviamente, nem me lembro se entendi algo, mas me lembro da sensação de estar diante de algo que era bom, precioso, interessante, de um lugar de exceção que se abria com aquele livro fundador no qual, aliás, há vários afundamentos, se fala de naufrágio, de afogamento.

Tudo isto colocado, eu gostaria de deixar um pouco de lado este momento de anamnese e de tentar organizar a minha resposta segundo uma proposta muito interessante, muito rica, de Luiz Fernando Medeiros de Carvalho sobre o meu segundo livro, Quase uma arte (2005), lançada durante um debate. Interpretando um dos poemas, inventando ali genialmente um princípio de leitura do livro, ele diz que o livro se escreve para trás e para frente.

Transcrevo o poema, apenas para contextualizar a proposta: 


\section{Acontecimento}

promovi um pequeno apocalipse

o acontecimento já se produzia

desde priscas eras

só precisei ajudar um pouco

prender a respiração

contar até mil de frente para trás

de trás para frente

virar a ampulheta

o fim de um mundo depende de mim

agora já foi

Imitando o gesto de Carvalho, vou tentar pensar para trás e para frente, não apenas em relação a este livro, mas em relação a toda a escrita literária que pratiquei até aqui, inclusive, e a uma escrita literária por vir, tal como ela me aparece vista desde este momento.

Em primeiro lugar, do ponto de vista dessa relação com uma origem (igualmente inventada, como todo o resto) da escrita, eu diria que escrever para trás é homenagear as leituras que fiz, toda a história da literatura, os livros que li e os que ainda vou ler, como fluxo, manancial, corrente subterrânea de escrita. Seria uma perspectiva meio barthesiana, segundo a qual a leitura desperta no leitor o desejo de se tornar autor, configurando o que ele chama de um erotismo da leitura. Neste patamar de reflexão, escrever para frente seria o jorro desse desejo tornando-se ele também escrita literária, indo encontrar o oceano de livros existentes para ali se perder. Nesse sentido, os escritores não deixariam de ser também, de certo modo, os trabalhadores do mar...

Mas para trás e para frente também se refere, como é o caso na ideia de Carvalho, a uma relação com a experiência. Para a circunstância, em direção ao trauma, e para além dele, em falas que alcançam o autor quando este já é outra pessoa. Para trás e para frente, memória e invenção da memória, a escrita outra torna o estar no mundo um momento sempre já reflexivo, acaba com a pretensão à espontaneidade e reforça o caráter inaugural da experiência literária que, finalmente, aparece como uma instância produtora da experiência de vida, ao ordená-la, interpretá-la, fazê-la significar, e não se limitar a meramente representá-la.

Isso vale em geral, para tentar descrever o movimento em direção a essa escrita outra. Eu gostaria de descrever um pouco cada parte desse movimento, ou seja, cada livro, melhor dizendo, o que move cada projeto de livro meu que se tornou um livro publicado ao encontro do oceano de livros. 
O primeiro livro, em 1999, A vida espiralada, foi o acesso primeiro, a entrada, mas também a crise, o encontro da poesia (do que naquela altura se acreditava ser a poesia) com a música (ou com o que então se entendia por música). Tudo partindo da concepção de um simbolismo que talvez nunca tenha existido como se imaginava. Uma primeira volta exorbitada em torno de Mallarmé, estrela próxima e distante, padroeiro, anjo barroco ou aleijado, torto, tonto de tanto projeto. A navegação exigiu alguns cálculos e algum tempo, o tempo de enfiar contas, ou pérolas, aos poucos.

O livro seguinte, em 2005: um quase. Quase uma arte. Para minha surpresa, o livro acabou como finalista de dois importantes prêmios literários brasileiros... quase. Título mallarmeano, ou mallarmaico, como queria Haroldo de Campos, remetendo ao lance de dados, esse "tudo ou nada” que só pode acabar de modo razoável em quase. Ele estabelece uma aposta em, como comenta R. Leicester, tradutor desse livro para o espanhol da Argentina, "una obra poética que no mejora ni empeora su personalidad, sino que la involucra apenas en su dudoso mérito de estar viva por ahora, como su lector." Gosto muito dessa perspectiva porque, justamente, ela esvazia a persona do poeta, a sua máscara.

Nesse livro, observo o surgimento de alguns animais de linguagem, ainda vivos quando os releio. No seu surpreendente e pensativo prefácio, intitulado $O$ animal que se desconhece, Marcos Siscar propõe que "O que o animal ensina é que a riqueza do corpo, sendo riqueza da letra, se oferece como enigma não apenas a ser decifrado, mas a ser percebido como tal."2 Imagino uma cena na qual alguém apareceria e me diria "A letra ou a vida!", lembrando-me do tempo em que o salteador atravessava o caminho do viajante e dizia "A bolsa ou a vida!". Entre a letra e a vida, escolho avidamente as duas.

Aqui se encena uma linha importante de reflexão, que o poema acolhe como ninguém: o jogo do próprio e do figurado. Quando digo que o poema acolhe esta reflexão como ninguém, entendo que essa expressão deve ser lida de maneira radical, nas duas direções ao mesmo tempo. Isso significaria que ele permite o estabelecimento dessa aposta, se mostrando melhor e mais hospitaleiro do que todos os demais lugares; e também que ele é um ponto de negatividade absoluta, pois nem nele

1. In http://www.salagrumo.org/notas.php?notaId=50. "Casi un arte", de Paula Glenadel, tradução e apresentação por R. Leicester. Está programada uma edição conjunta Grumo/Vox do livro inteiro.

2. In SISCAR, Marcos Antonio. O animal que se desconhece. Prefácio ao livro Quase uma arte. São Paulo; Rio de Janeiro: Cosac Naify; 7 Letras, 2005. 
se valoriza essa aposta. O poema, como as máscaras gêmeas do teatro, ri e chora. O lugar, contudo, mallarmeanamente, se mantém, em sua ambivalência.

O terceiro livro, em 2008, A fábrica do feminino, representou um encontro com o feminino? Sem dúvida. Mas ao escrevê-lo, o feminino foi aparecendo como a própria e principal dúvida. Livro político, como aponta Ana Luísa Amaral no generoso posfácio que elaborou para ele, pois duvidar do feminino é primeiramente duvidar do masculino e, em seguida, duvidar do poder, da fábrica que os separa, para uni-los numa polis utópica, em que podemos nos sentir em casa com as nossas dúvidas domésticas. Domesticar passa a não parecer tão mau, a partir do momento em que esse espaço não está desvalorizado como reino da nadería, a partir do momento em que não se acredita mais na superioridade inconteste de outros espaços. Assim, por exemplo, foi possível sair de Mallarmé para voltar novamente a Mallarmé, mas desta vez a um Mallarmé esquisito, meio cinematográfico, transformado em personagem, ligeiramente domesticado, isto é, entortado de outra maneira.

Partindo daqui se articula um encontro futuro, entre a poesia e o teatro, matriz de um projeto atual em que se está procurando dar às muitas vozes que compõem o poema uma existência ou consistência teatral mais formal, o que é muito agradável, uma vez que no poema a tendência acaba sendo a de buscar uma unicidade de enunciação, porque o poeta empresta o seu lugar às vozes, mas em determinado momento o pede de volta: acabou a brincadeira.

$\mathrm{E}$ o fato de eu (que sou a inventora da poeta) estar respondendo (por ela) à pergunta Por que escreve? mostra isso muito bem. No teatro, pelo menos tal como ele está sendo pensado aqui em direção ao poema, nesse mínimo teatro que eu imagino (uma mise en scène spirituelle, diria ainda o santo Mallarmé), a autonomia das vozes é um espetáculo do qual inclusive o tenebroso "eu lírico" pode desfrutar. Então, eu posso me imaginar pedindo a um dos personagens para responder a essa pergunta e me divertindo com a sua resposta.

3. AMARAL, Ana Luísa. Da falta, ou do excesso: fabricar o poético. Posfácio ao livro A fábrica do feminino. RJ: 7 Letras, 2008. Publicado com o apoio do MinC/Petrobras. 
